Article

\title{
Unavoidable Destroyed Exergy in Crude Oil Pipelines due to Wax Precipitation
}

\author{
Qinglin Cheng *, JinWei Yang, Anbo Zheng, Lu Yang, Yifan Gan and Yang Liu
}

Key Lab of Ministry of Education for Enhancing the Oil and Gas Recovery Ratio, Northeast Petroleum University, Daqing 163318, China; jinwei.yang@cnpc.com.cn (J.Y.); 18245691497@163.com (A.Z.); yanglushiyou517@163.com (L.Y.); ganyifan0718@stu.nepu.edu.cn (Y.G.); lynepu@126.com (Y.L.)

* Correspondence: chengqinglin7212@163.com

Received: 15 October 2018; Accepted: 8 January 2019; Published: 12 January 2019

\begin{abstract}
Based on the technological requirements related to waxy crude oil pipeline transportation, both unavoidable and avoidable destroyed exergy are defined. Considering the changing characteristics of flow pattern and flow regime over the course of the oil transportation process, a method of dividing station oil pipelines into transportation intervals is suggested according to characteristic temperatures, such as the wax precipitation point and abnormal point. The critical transition temperature and the specific heat capacity of waxy crude oil are calculated, and an unavoidable destroyed exergy formula is derived. Then, taking the Daqing oil pipeline as an example, unavoidable destroyed exergy in various transportation intervals are calculated during the actual processes. Furthermore, the influential rules under various design and operation parameters are further analyzed. The maximum and minimum unavoidable destroyed exergy are $381.128 \mathrm{~kJ} / \mathrm{s}$ and $30.259 \mathrm{~kJ} / \mathrm{s}$. When the design parameters are simulated, and the maximum unavoidable destroyed exergy is $625 \mathrm{~kJ} / \mathrm{s}$ at the diameter about $250 \mathrm{~mm}$. With the increase of insulation layer thickness, the unavoidable destroyed exergy decreases continuously, and the minimum unavoidable destroyed exergy is $22 \mathrm{~kJ} / \mathrm{s}$ at $30 \mathrm{~mm}$. And the burial depth has little effect on the unavoidable destroyed exergy. When the operation parameters are simulated, the destroyed exergy increases, but it is less affected by the outlet pressure. The increase amplitude of unavoidable destroyed exergy will not exceed $2 \%$ after the throughput rises to $80 \mathrm{~m}^{3} / \mathrm{h}$. When the outlet temperature increases until $65{ }^{\circ} \mathrm{C}$, the loss increase range will not exceed $4 \%$. Thus, this study provides a theoretical basis for the safe and economical transportation of waxy crude oil.
\end{abstract}

Keywords: waxy crude oil; pipeline transportation; characteristic temperature; the unavoidable destroyed exergy

\section{Introduction}

The crude oil produced in China is mostly condensate and viscous crude oil. Heated transportation is often used in pipe transmission, which often leads to high energy consumption in pipeline operations. Building a scientific evaluation system for energy consumption is important for energy efficiency management [1]. For example, Wang [2] introduced the ton oil gas consumption coefficient $\varphi$ and suggested a new method of gas consumption evaluation for crude oil gathering and transportation systems. The advantages and disadvantages of the management process can be evaluated by comparing $\varphi$ to determine the disparity between various systems and oil fields and promote the development of energy-saving work. Zuo et al. [3] referred to the concept of hydraulic horse power (HHP)—used by Enbridge and other pipeline companies-and introduced two new energy consumption evaluation indices for long-distance pipelines. These indices shift the discussion of energy consumption from the power station (oil station/compressor station) to the energy consuming section itself. Probert et al. [4] provided a theoretical basis for predicting the optimal thickness 
of insulation materials required for such pipelines, so as to achieve the smallest energy operation. Nguyen et al. [5] show that the oil platform is an energy-intensive system. Referring to the nature of oil, export specifications and oil field life, the energy used by each facility ranges from several megawatts to several hundred megawatts, and the overall system is energy-saving in terms from equipment size and process integration.

In recent years, exergy has been regarded as an energy consumption evaluation index in thermodynamics. Exergy denotes that part of energy quantity that can be transformed into useful work to the utmost degree when substance or material flow changes reversibly from any state to a given environment equilibrium state. The concept exergy, which organically combines "quality" and "quantity" of energy and reflects the real value of energy, has made all kinds of energy comparable and solved the puzzling problem that none of the parameters can be singly used to assess the value of energy in thermodynamics and energy science. It also changed traditional ideas about energy character, energy loss and energy transformation efficiency, etc [6-9].

The exergy analysis method addresses the deficiency of the first law of thermodynamics, which simply analyzes energy from the "quantity" relation and has been introduced into the energy consumption analysis of crude oil pipelines in recent years. Zhang [10] stated that the crude oil transportation process must be accompanied by the consumption of propulsion exergy. Based on this exergy analysis principle, the exergy analytical model of crude oil transportation is established. The formula for propulsion exergy consumption is derived, and the change in propulsion exergy consumption due to operation parameters is analyzed to lay the foundation for pipe exergy flow classification. Based on external destroyed exergy and internal exergy dissipation, Li [11], starting with the substance being transported in the pipeline, published a study dividing exergy flow into effective exergy consumption and invalid exergy consumption and derived a method to calculate them.

Conventional exergy analysis can only suggest the potential or possibility of thermodynamic process improvements, but it cannot note whether the improvement is feasible. In the actual thermodynamic process, temperature difference, pressure difference and chemical potential difference are driving forces. The existence of driving forces inevitably leads to destroyed exergy-and the greater the driving force, the faster the process, and the greater the destroyed exergy. However, to carry out the thermal process and cycle, there must be a driving force, which inevitably leads to destroyed exergy [12].

Therefore, for pipeline transportation with irreversible phenomena, such as temperature difference and friction flow, effective improvement measures based on differentiating unavoidable and avoidable destroyed exergy are necessary for energy savings. This analysis method accurately points out the maximum destroyed exergy location, can provide a basis for identifying the weak links of energy utilization and can be used to analyze the imperfection of various thermodynamic cycles. The application of thermodynamics in engineering practice has been broadened. It can be concluded that the method can provide accurate, reliable and valuable research and analysis results for various industrial sectors.

\section{Definition of Unavoidable Destroyed Exergy}

Tsatsaronis and Park et al. first brought up the concept of unavoidable destroyed exergy in their paper in 2002 [13]. For crude oil transportation, there must be a theoretical temperature drop and theoretical pressure drop to ensure the safe and economical transportation of crude oil; the corresponding destroyed exergy is unavoidable destroyed exergy. The excess theoretical value in the actual transportation process is avoidable destroyed exergy, i.e., in the actual conveying process, the part that exceeds the theoretical value is avoidable destroyed exergy. In this way, the destroyed exergy of conventional exergy analysis can be divided into two parts: unavoidable destroyed exergy $E_{x, U}$ and avoidable destroyed exergy $E_{x, A}$; thus, total destroyed exergy $E_{x}$ is:

$$
E_{x}=E_{x, U}+E_{x, A}
$$


The heat loss and friction loss in pipe transportation are considered to correspond to thermal destroyed exergy and pressure destroyed exergy, respectively. There must be a technical or economic theoretical minimum temperature difference in the crude oil transportation process, and the thermal destroyed exergy caused by corresponding temperature difference $\Delta T$ is the minimum thermal destroyed exergy. The driving force used to overcome oil flow viscous frictional resistance and ensure the smooth advance of the crude oil from the initial point to the end of the pipe is the minimum pressure destroyed exergy of the start and end pressure drop $\Delta p$. Therefore, to ensure safe and economical operation of crude oil pipelines, the theoretical temperature and pressure drops are obtained, so there exists corresponding theoretical minimums $E_{x}(T)_{\min }$ and $E_{x}(p)_{\min }$ of thermal destroyed exergy and pressure destroyed exergy. Then, their sum is the unavoidable destroyed exergy in the crude oil transportation process [12], thus:

$$
E_{x, U}=E_{x}(T)_{\min }+E_{x}(p)_{\min }
$$

After dividing destroyed exergy into avoidable and unavoidable destroyed exergy, the improvement of the crude oil pipeline process will change from a general reduction of destroyed exergy to the decrease of avoidable destroyed exergy and minimization of unavoidable destroyed exergy.

\section{Determination of Unavoidable Destroyed Exergy for Waxy Crude Oil}

With the decrease in the pipeline temperature and the precipitation of the wax crystals in the oil, the crude oil may be transformed from a Newtonian fluid to a non-Newtonian fluid. With the reduction of pipeline transportation throughput and the decrease of the pipeline transport temperature, the tube segments of the non-Newtonian flow pattern will lengthen [14]. Considering the different rheological properties of crude oil in different temperature ranges, a method is proposed to divide the oil pipeline into transportation intervals according to characteristic temperatures, such as wax appearance point, critical transition temperature and anomalous point. A formula for calculating the unavoidable destroyed exergy of crude oil under different flow conditions is derived.

\subsection{Crude Oil Critical Transition Temperature}

Considering the stable operation of an oil pipeline, the Reynolds number of the same crude oil can be expressed as a function of temperature. The critical transformation temperature of the flow pattern and flow regime can be calculated by the critical Reynolds number inverse calculation. In this method, traditional flow regime judgment (based on Reynolds number) and flow pattern judgment (using the anomalous point $T_{F}$ as the standard) are unified to use the pipeline temperature as the basis for judgment $[15,16]$.

For Newtonian waxy crude oil, the critical Reynolds number is 2000 for internal flow [17] when the flow of the Newtonian fluid is converted from laminar to turbulent. Reynolds number is defined as:

$$
\operatorname{Re}=\frac{D v}{v}=\frac{D \rho v}{\mu}
$$

where, $D$-Inner diameter of oil pipeline, $\mathrm{m}$; v—Crude oil flow velocity, $\mathrm{m} / \mathrm{s} ; \mathrm{v}$-Oil flow viscosity, $\mathrm{m}^{2} / \mathrm{s}$.

It should be noted that when calculating the transition temperature, the viscosity of the oil flow for Newtonian flow is calculated based on the critical Reynolds number $\operatorname{Re}_{c}$. According to its viscosity temperature curve, $T_{c}$ is obtained.

For non-Newtonian waxy crude oil, the specification provides that the critical Reynolds number is 2000, which marks the change from laminar flow to turbulent flow, and the Reynolds number is defined as follows [17]:

$$
\operatorname{Re}_{M R c}=\frac{\rho D^{n^{\prime}} v^{2-n^{\prime}}}{\frac{K^{\prime}}{8}\left(\frac{6 n^{\prime}+2}{n^{\prime}}\right)^{n^{\prime}}}
$$


where, $\rho$-Density of crude oil, $\mathrm{kg} / \mathrm{m}^{3} ; K^{\prime}$ —Consistency coefficient of crude oil, Pa.s; $n^{\prime}$-Rheological index of crude oil.

When waxy crude oil becomes a non-Newtonian fluid, it is usually a pseudoplastic fluid. In the temperature range of pseudoplastic fluid, the definition $\operatorname{Re}_{M R c}$ and its rheological parameters $n^{\prime}$ and $K^{\prime}$ can be expressed as a function of temperature. Using Formulas (5) and (6), the flow transition temperature can be back calculated. That is [18]:

$$
\begin{aligned}
& K^{\prime}=A_{1} e^{-B_{1} T} \\
& n^{\prime}=A_{2}+B_{2} T
\end{aligned}
$$

where, $A_{1}, A_{2}, B_{1}, B_{2}$ - constant.

\subsection{Determination of the Specific Heat Capacity of Waxy Crude Oil}

It should be noted that wax deposition may occur during the transportation of waxy crude oil. The total heat transfer coefficient of the pipeline gradually decreases with the increase of the thickness of the wax layer. There will be a wax-free section, an initial paraffin section and a wax deposition tail section in the oil pipeline, and the specific heat capacities of the oil are different in each section:

(1) When the oil temperature is higher than the wax appearance temperature of waxy crude oil, there is no wax phenomenon in the crude oil pipeline (this is called the wax-free section). In this temperature range, the specific heat capacity of crude oil increases slowly with the rise of temperature. The relationship is [19]:

$$
c=\frac{1}{\sqrt{\rho_{4}^{15}}}\left(1.687+3.39 \times 10^{-3} T\right)
$$

where, $c$-The crude oil specific heat capacity, $\mathrm{kJ} /\left(\mathrm{kg} \cdot{ }^{\circ} \mathrm{C}\right) ; \rho_{4}^{15}$ - The crude oil relative density at $15{ }^{\circ} \mathrm{C}$, dimensionless; $\mathrm{T}$ - the crude oil temperature, ${ }^{\circ} \mathrm{C}$.

(2) When the temperature of the oil is lower than the wax appearance point, the wax will precipitate. In particular, after the oil temperature drops to the wax appearance point of crude oil, the wax in the pipeline will increase, and the wax layer will gradually thicken along the oil delivery direction until a peak is reached-that is, the maximum thickness of wax deposition. This section is called the initial paraffin section. Due to the release heat from the wax crystal in the above temperature range, the specific heat capacity of crude oil increases with decreasing temperature, and the relationship between crude oil and temperature fits the following formula [19]:

$$
c=4.186-A e^{a T}
$$

where, $A$-constant, different from crude oil, $\mathrm{kJ} /\left(\mathrm{kg} \cdot{ }^{\circ} \mathrm{C}\right)$; $a$-constant, different from crude oil, $1 /{ }^{\circ} \mathrm{C}$.

(3) From the peak point of wax deposition to the interval of crude oil intakes, it is called the wax deposition tail section. With the increase of wax deposit thickness, the operation conditions of oil pipelines correspondingly change. In this temperature range, the specific heat capacity of crude oil decreases with decreasing oil temperature. The relationship between specific heat and crude oil temperature in this interval can be expressed as [19]:

$$
c=4.186-B e^{-m T}
$$

where, $B$ - constant, different from crude oil, $\mathrm{kJ} /\left(\mathrm{kg} \cdot{ }^{\circ} \mathrm{C}\right) ; m$ - constant, different from crude oil, $1 /{ }^{\circ} \mathrm{C}$. The parameters of several waxy crude oils are shown in Table 1. 
Table 1. The parameters for four kinds of crude oil [19].

\begin{tabular}{ccccc}
\hline Parameter & $\boldsymbol{A}$ & $\boldsymbol{B}$ & \multicolumn{1}{c}{$\boldsymbol{n}$} & $\boldsymbol{m}$ \\
\hline Shengli crude oil & 0.4840 & 1.9255 & 0.03465 & 0.01164 \\
Daqing crude oil & 0.9085 & 1.7585 & 0.01732 & 0.01567 \\
Puyang crude oil & 0.6753 & 1.7258 & 0.0264 & 0.01217 \\
Renqiu crude oil & 0.1970 & 1.8880 & 0.0476 & 0.02117 \\
\hline
\end{tabular}

\subsection{Temperature Range of Pipeline Transportation}

In the process of pipeline transportation, the specific heat capacity of oil and viscous frictional resistance vary with temperature; thus, the oil pipeline is divided into temperature intervals according to the wax appearance point $T_{s l}$, anomalous point $T_{F}$ and flow transition temperature $T_{\mathcal{C}}, T_{M R c}$. Specifically [20-22]:

(1) If the temperature range is $T_{z} \geq T_{s l}$, there is only a single temperature range $T_{R} \geq T \geq T_{z}$ in the pipeline transportation, and the crude oil will remain in the Newtonian turbulence state;

(2) If the temperature range is $T_{s l} \geq T_{z}$ and $T_{z} \geq T_{c}$, the pipeline transportation process is divided into two temperature intervals $T_{R} \geq T \geq T_{s l}$ and $T_{s l} \geq T \geq T_{z}$; thus, the pipeline crude oil is in the Newtonian flow state;

(3) If the temperature range is $T_{s l} \geq T_{z}$ and $T_{z} \geq T_{F}$, the pipeline transportation process is divided into three temperature intervals $T_{R} \geq T \geq T_{s l}, T_{s l} \geq T \geq T_{c}$ and $T_{c} \geq T \geq T_{z}$; thus, the pipeline crude oil is in Newtonian flow and there may be laminar flow state;

(4) If the temperature range is $T_{s l} \geq T_{z}$ and $T_{z} \geq T_{M R c}$, pipeline transportation is divided into four temperature intervals $T_{R} \geq T \geq T_{s l}, T_{s l} \geq T \geq T_{\mathcal{c}}, T_{\mathcal{c}} \geq T \geq T_{F}$ and $T_{F} \geq T \geq T_{z}$; thus, non-Newtonian fluid characteristics begin to appear;

(5) If the temperature range is $T_{s l} \geq T_{z}$ and $T_{z} \leq T_{M R c}$, pipeline transportation is divided into five temperature intervals $T_{R} \geq T \geq T_{s l}, T_{s l} \geq T \geq T_{c}, T_{c} \geq T \geq T_{F}, T_{F} \geq T \geq T_{M R c}$ and $T_{M R c} \geq T \geq T_{z}$; thus, the pipeline crude oil presents non-Newtonian laminar flow in some pipe sections.

The division of the temperature range for a waxy crude oil pipeline is shown in Figure 1.

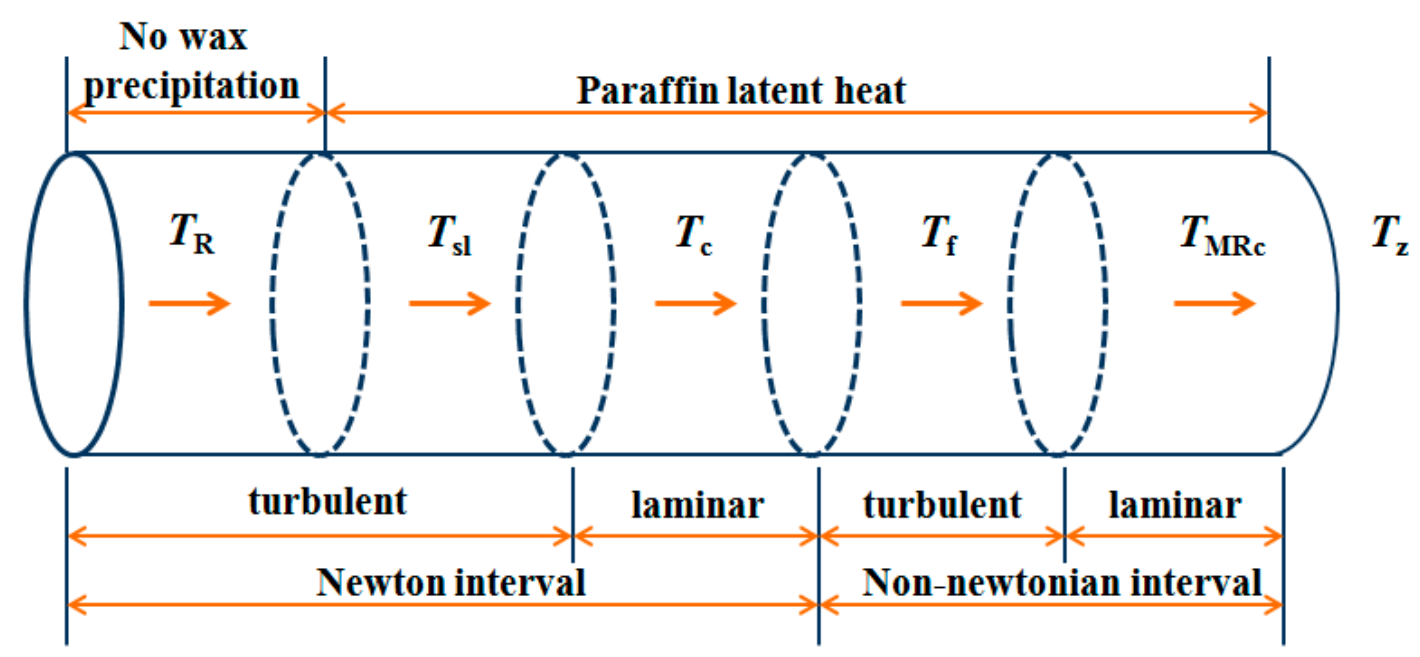

Figure 1. The division of the temperature range for a waxy crude oil pipeline.

During crude oil transportation, $T_{0}$ is the ambient temperature around the pipeline, $G$ is the throughput of oil transported by the pipeline and $i$ is the hydraulic gradient. When fluid flows through pipe section $\mathrm{d} L$, the corresponding temperature drop is $\mathrm{d} T$. The energy balance of elementary section $\mathrm{d} L$ under stable conditions for a waxy crude oil pipeline is [23]:

$$
K \pi D\left(T-T_{0}\right) \mathrm{d} L=-G c \mathrm{~d} T+g G i \mathrm{~d} L
$$


For Formula (10), the left is the heat dissipation from the $\mathrm{d} L$ pipe to the surrounding medium in unit time. The first item at the right is the heat release from the temperature drop $\mathrm{d} T$ of the oil flow in the pipe. The second item is the heat transformed by friction loss of oil flow in $\mathrm{d} L$ section.

The total length of the wax oil pipeline is the sum of the temperature range lengths for each oil transportation, and the temperature intervals lengths of the pipeline are calculated. The length of each temperature range $L_{i}$ can be obtained according to the Formula (11).

$$
L_{i}=\frac{G c}{K \pi D} \ln \frac{T_{R}-\left(T_{0}+b\right)}{T_{L}-\left(T_{0}+b\right)}\left(b=\frac{g i G}{K \pi D}\right)
$$

where, $T_{R}$-Initial point temperature of the crude oil pipeline transportation temperature range, ${ }^{\circ} \mathrm{C}$; $T_{L}$-Terminal point temperature of the crude oil pipeline transportation temperature range, ${ }^{\circ} \mathrm{C}$.

\subsection{Calculation of Unavoidable Destroyed Exergy}

\subsubsection{Unavoidable Thermal Destroyed Exergy}

According to the definition of unavoidable destroyed exergy, its calculation can be simplified as the calculation of the theoretical minimum temperature difference for pipe transmission. Considering the influence of leakage and insulation damage during the actual operation of a crude oil pipeline, the measured terminal temperature will generally be lower than the theoretical terminal oil temperature. Therefore, under the premise of meeting crude oil pipeline transportation technology requirements, the theoretical terminal temperature $T_{z l}$ is generally $3{ }^{\circ} \mathrm{C}$ above the condensation point. The theoretical minimum temperature difference $\Delta T$ is the difference between the theoretical initial point temperature of the oil pipeline and the theoretical terminal temperature, and the theoretical outstation temperature $T_{R l}$ of the crude oil can be derived using the Sukhov formula [23]. That is:

$$
T_{R l}=T_{0}+\left(T_{Z l}-T_{0}\right) e^{-a L}
$$

Considering the different temperature ranges in crude oil transportation, it is necessary to deduce the theoretical initial and terminal temperatures in each temperature range from the theoretical end temperature. Then, the theoretical outstation station temperature is:

$$
T_{R l}=T_{0}+\left(T_{Z l, i}-T_{0}\right) e^{-a L_{i}} \quad\left(a=\frac{K \pi D}{G c}\right)
$$

The unavoidable thermal destroyed exergy in the crude oil transportation process is the sum of the unavoidable thermal destroyed exergy from each temperature range.

$$
E_{x, U}(T)=\sum_{i=1}^{n} G c\left(T_{R i}-T_{L i}-T_{0} \ln \frac{T_{R i}}{T_{L i}}\right)
$$

\subsubsection{Unavoidable Pressure Destroyed Exergy}

During crude oil transportation, when fluid flows through pipe section $\mathrm{d} l$, the pressure difference corresponding to that pipe section is $\Delta p$. The stress area is the pipeline cross section, so the unavoidable pressure destroyed exergy in this section is:

$$
E_{x, U}(p)=\Delta p \times S \mathrm{~d} L
$$

where S-Pipe cross-section area, $\mathrm{m}^{2}$.

The unavoidable pressure destroyed exergy in the whole pipe section is:

$$
E_{x, U}(p)=\int_{0}^{L} \Delta p \times S \mathrm{~d} L
$$


The calculation of frictional pressure drop must consider the flow pattern and flow regime of crude oil during transportation. For Newtonian fluids, the formula for pipeline frictional pressure drop is:

$$
\Delta p=\rho g h \quad\left(h=\beta \frac{Q^{2-m} v_{p}^{m}}{D^{5-m}} L\right)
$$

where, $h$-Friction loss, $\mathrm{m} ; Q$-Pipe volume flow, $\mathrm{m}^{3} / \mathrm{s} ; L$-Pipeline length, $\mathrm{m}$.

For non-Newtonian fluid, the formula for pipeline frictional pressure drop is:

For laminar flow [15]:

$$
\Delta p=\frac{4 L K}{D}\left(\frac{3 n+1}{4 n}\right)^{n}\left(\frac{8 v}{D}\right)^{n}=4 L K\left[\frac{8(3 n+1)}{\pi n}\right]^{n} \frac{Q^{n}}{D^{3 n+1}}
$$

For turbulent flow [15]:

$$
\Delta p=\lambda \frac{L}{D} \frac{\rho v^{2}}{2}=4 f \frac{L}{D} \frac{\rho v^{2}}{2}
$$

where, $\lambda, f$-Friction coefficient of power law fluid, which generally uses the Dodge-Metzner semi-empirical formula for confirmation:

$$
\frac{1}{\sqrt{f}}=\frac{4.0}{n^{\prime 0.75}} \lg \left[\operatorname{Re}_{M R} f^{\left(1-\frac{n^{\prime}}{2}\right)}\right]-\frac{0.4}{n^{\prime 1.2}}
$$

Finally, when calculating the unavoidable pressure destroyed exergy, it is necessary to combine the pipe temperature range. The unavoidable destroyed exergy of each interval can be obtained using the integral of (18), wherein the temperature range of Newtonian crude is:

$$
E_{x, U i}(p)=\int \frac{\pi}{4} \beta \frac{Q^{2-m} v^{m} L_{i} \rho g}{D^{3-m}} \mathrm{~d} L=\frac{\pi \beta Q^{2-m} v^{m} L_{i}^{2} \rho g}{8 D^{3-m}}
$$

For the temperature range of non-Newtonian crude oil.

For laminar flow:

$$
E_{x, U i}(p)=\frac{\pi K^{\prime} Q^{n^{\prime}} L_{i}{ }^{2}}{2 D^{3 n^{\prime}-1}}\left[\frac{8\left(3 n^{\prime}+1\right)}{\pi n^{\prime}}\right]^{n^{\prime}}
$$

For turbulent flow:

$$
E_{x, U i}(p)=\int \frac{\pi}{4} \times 0.3304 f \frac{Q^{2}}{D^{5}} \times \rho g L_{i} \mathrm{~d} L=0.1297 f \rho g \frac{Q^{2} L_{i}^{2}}{D^{5}}
$$

Therefore, the unavoidable pressure destroyed exergy during crude oil transportation is the sum of the unavoidable pressure destroyed exergy from each temperature range:

$$
E_{x, U}(p)=\sum_{i=1}^{n} E_{x, U i}(p)
$$

\subsection{The Calculation Process of Unavoidable Destroyed Exergy}

To summarize, the unavoidable destroyed exergy calculation process for pipeline transportation is shown in Figure 2. 


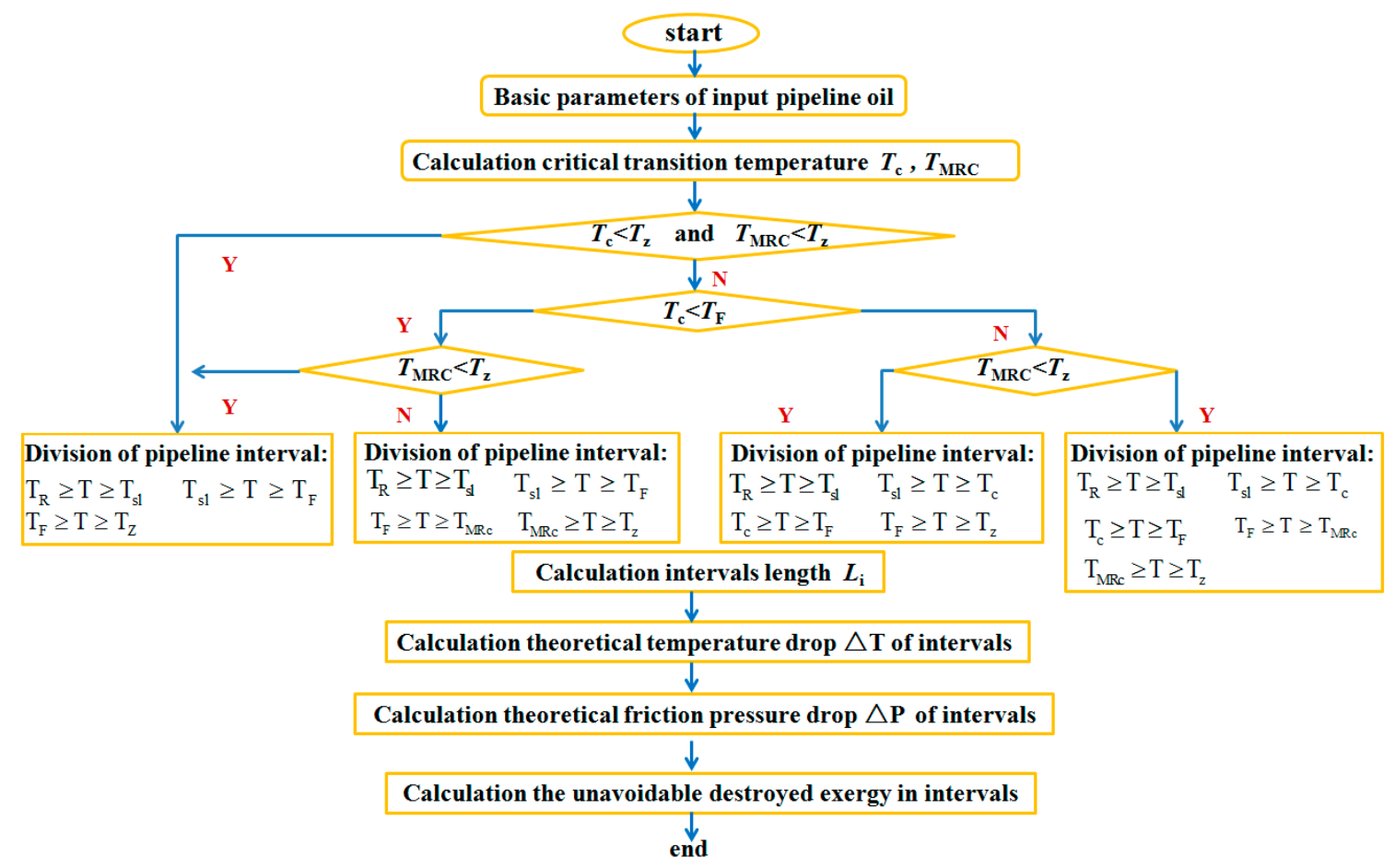

Figure 2. Unavoidable destroyed exergy calculation flow chart for crude oil pipeline transportation process.

\section{Calculation Example}

\subsection{Basic Data}

Taking an oil pipeline in the Daqing oilfield as an example, crude oil pipeline transportation is simulated; the basic operating and physical parameters of the crude oil pipeline are shown in Table 2.

Table 2. Basic operating parameters of a Daqing oil pipeline.

\begin{tabular}{cccc}
\hline Item & Data & Item & Data \\
\hline Pipeline length & $45121 \mathrm{~m}$ & Pipeline diameter & $\Phi 219 \times 5.6 \mathrm{~mm}$ \\
Buried depth & $1600 \mathrm{~mm}$ & Wax Appearance point & $47.7^{\circ} \mathrm{C}$ \\
Outstation temperature & $65^{\circ} \mathrm{C}$ & Anomalous point & $36.2^{\circ} \mathrm{C}$ \\
Outstation pressure & $4.5 \mathrm{MPa}$ & Condensation point & $25^{\circ} \mathrm{C}$ \\
Pipeline throughput & $70 \mathrm{~m}^{3} / \mathrm{h}$ & Density $\left(30^{\circ} \mathrm{C}\right)$ & $860 \mathrm{~kg} / \mathrm{m}^{3}$ \\
Ambient temperature & $-4.4^{\circ} \mathrm{C}$ & Density $\left(50^{\circ} \mathrm{C}\right)$ & $830 \mathrm{~kg} / \mathrm{m}^{3}$ \\
Soil thermal conductivity & $1.4 \mathrm{~W} /\left(\mathrm{m} \cdot{ }^{\circ} \mathrm{C}\right)$ & Viscosity $\left(30^{\circ} \mathrm{C}\right)$ & $70 \mathrm{mPa} \cdot \mathrm{s}$ \\
Pipe thermal conductivity & $45.24 \mathrm{~W} /\left(\mathrm{m} \cdot{ }^{\circ} \mathrm{C}\right)$ & Viscosity $\left(50^{\circ} \mathrm{C}\right)$ & $9.41 \mathrm{mPa} \cdot \mathrm{s}$ \\
\hline
\end{tabular}

\subsubsection{Critical Transition Temperature}

Using the basic equations, Newtonian flow transition temperature $T_{\mathcal{C}}$ is $30.8{ }^{\circ} \mathrm{C}$, and nonNewtonian transformation temperature $T_{M R c}$ is $32.1^{\circ} \mathrm{C}$.

\subsubsection{Pipeline Transmission Temperature Intervals}

According to the axial temperature distribution curve of the oil pipeline, the crude oil inlet station temperature is $36.2^{\circ} \mathrm{C}$. Therefore, the whole oil pipeline can be divided into three intervals according to the transportation temperature:

Newtonian hydraulic smooth region (above the wax appearance point, $T_{R}>T>T_{s l}$ ), Newtonian hydraulic smooth region (below the wax appearance point, $T_{s l}>T>T_{F}$ ) and Non-Newtonian turbulent region $\left(T_{F}>T>T_{Z}\right)$; the interval lengths are $20,755 \mathrm{~m}, 18,950 \mathrm{~m}$ and $5414 \mathrm{~m}$, respectively, and the temperature region of waxy crude oil is obtained as shown in Figure 3: 


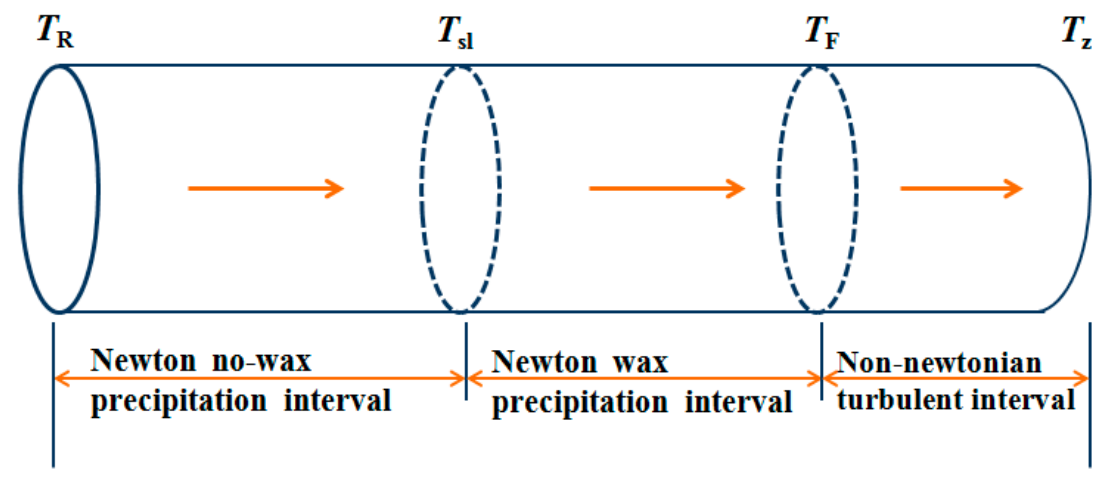

Figure 3. Temperature regions of a waxy crude oil.

\subsubsection{Theoretical Outstation Temperature}

The waxy crude oil condensation point is $25^{\circ} \mathrm{C}$ and the theoretical inlet temperature $\mathrm{T}_{l z}$ is $28^{\circ} \mathrm{C}$, which meet crude oil pipeline transportation technology requirements. According to the formula, the outstation temperatures of the crude oil in the Non-Newtonian turbulence interval, Newtonian turbulent wax precipitation interval and Newtonian turbulent non-wax precipitation interval are $38.54{ }^{\circ} \mathrm{C}, 45.28{ }^{\circ} \mathrm{C}$ and $46.05^{\circ} \mathrm{C}$, respectively.

\subsection{Calculation Results and Analysis of Unavoidable Destroyed Exergy}

According to the basic pipeline transportation data, the unavoidable destroyed exergy of the oil pipeline is calculated. The results are shown in Table 3.

Table 3. The calculation results of unavoidable destroyed exergy in the waxy crude oil pipeline transportation process.

\begin{tabular}{ccccc}
\hline $\begin{array}{c}\text { Pipeline Transmission } \\
\text { Temperature Region }\end{array}$ & $\begin{array}{c}\text { Newton Turbulent } \\
\text { Non-Wax } \\
\text { Precipitation }\end{array}$ & $\begin{array}{c}\text { Newton Turbulent } \\
\text { Wax Precipitation }\end{array}$ & $\begin{array}{c}\text { Non-Newton } \\
\text { Turbulence }\end{array}$ & $\begin{array}{c}\text { Whole Process of } \\
\text { Crude Oil Pipeline } \\
\text { Transportation }\end{array}$ \\
\cline { 2 - 5 } & $\boldsymbol{T}_{\boldsymbol{R}} \geq \boldsymbol{T} \geq \boldsymbol{T}_{s l}$ & $\boldsymbol{T}_{s l} \geq \boldsymbol{T} \geq \boldsymbol{T}_{\boldsymbol{F}}$ & $\boldsymbol{T}_{\boldsymbol{F}} \geq \boldsymbol{T} \geq \boldsymbol{T}_{\boldsymbol{Z}}$ & $\boldsymbol{T}_{\boldsymbol{R}} \geq \boldsymbol{T} \geq \boldsymbol{T}_{\boldsymbol{z}}$ \\
\hline $\begin{array}{c}\text { The unavoidable pressure } \\
\text { destroyed exergy (kJ/s) }\end{array}$ & 7.749 & 15.828 & 0.042 & 23.621 \\
\hline $\begin{array}{c}\text { The unavoidable thermal } \\
\text { destroyed exergy (kJ/s) }\end{array}$ & 373.379 & 315.716 & 30.217 & 719.313 \\
\hline $\begin{array}{c}\text { The unavoidable destroyed } \\
\text { exergy (kJ/s) }\end{array}$ & 381.128 & 331.544 & 30.259 & 742.934 \\
\hline $\begin{array}{c}\text { The ratio between unavoidable } \\
\text { pressure destroyed exergy and } \\
\text { pressure destroyed exergy (\%) }\end{array}$ & 9.409 & 22.202 & 0.328 & 14.178 \\
\hline $\begin{array}{l}\text { The ratio between unavoidable } \\
\text { thermal destroyed exergy and } \\
\text { thermal destroyed exergy (\%) }\end{array}$ & 58.429 & 61.883 & 34.786 & 58.193 \\
\hline
\end{tabular}

According to the data in the table, the unavoidable thermal destroyed exergy in the pipeline transportation of wax crude oil accounts for an overwhelming majority of the unavoidable destroyed exergy (95-99\%). This further proves the decisive role of temperature research in the analysis of crude oil transportation. By comparing the temperature regions of pipeline transmission, unavoidable destroyed exergy is larger in the interval $T_{R}>T>T_{s l}$. This is mainly due to the higher temperature of crude oil at the initial stage of pipeline transportation and the larger temperature difference and larger pressure difference between the surrounding environment and the medium. In the $T_{s l}>$ $T>T_{F}$ interval, the ratio of unavoidable thermal destroyed exergy increases in the pipeline. This is mainly because, with the gradual decrease of pipe temperature, pipe heat dissipation correspondingly decreases relative to the last pipe transportation interval; thus, there is a great reduction of thermal 
destroyed exergy. Because of wax precipitation in pipeline, the resistance increases, so the pressure difference increases. Therefore the unavoidable pressure destroyed exergy rises rapidly.

In the interval $T_{F}>T>T_{Z}$, unavoidable destroyed exergy is smallest. The main reason for this is that the operation temperature and pressure of the pipeline are decreasing, and the trend is gentle in late-stage oil pipeline transportation. The state is close to that of the surrounding medium, and temperature and pressure differences decrease continuously, which minimizes the unavoidable destroyed exergy of the pipeline.

According to the basic data of the pipeline transport process, unavoidable pressure destroyed exergy, unavoidable thermal destroyed exergy and unavoidable total destroyed exergy are calculated; their distribution along distance shown in Figure 4.

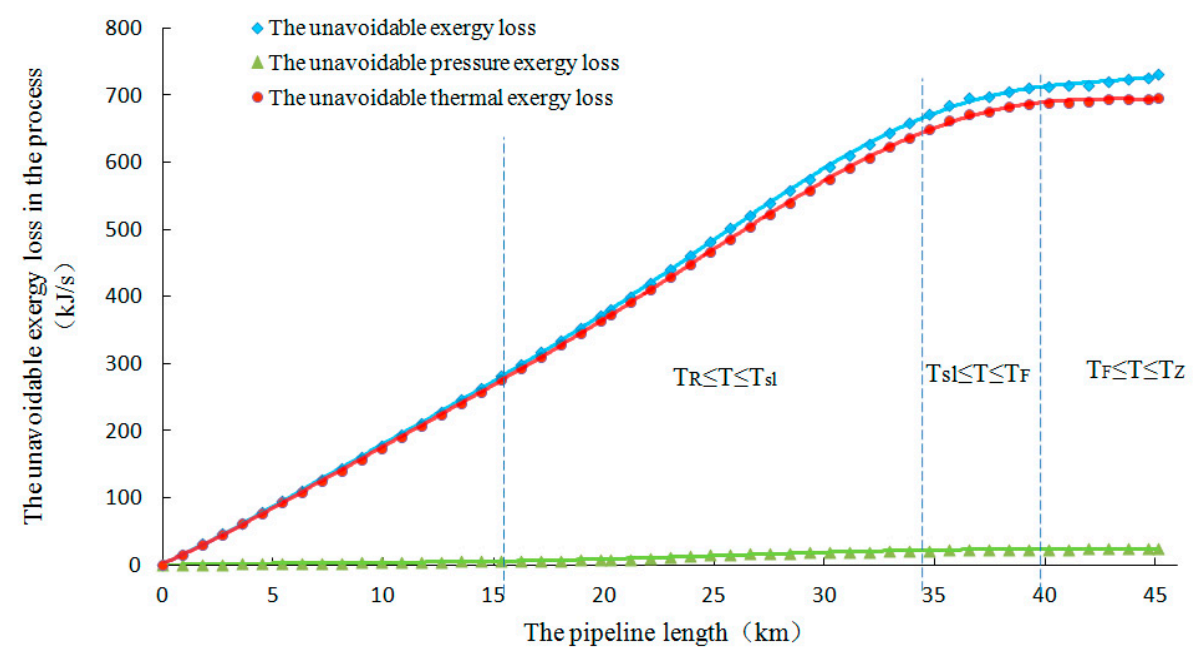

Figure 4. Unavoidable destroyed exergy distribution curve of the waxy crude oil pipeline

It can be seen from the figures that the curve of unavoidable destroyed exergy in Newtonian hydraulic smooth intervals $\left(T_{q}>T>T_{s l}, T_{s l}>T>T_{F}\right)$ is greater than that of the non-Newtonian turbulence intervals, which considers the changing flow pattern and flow regime with the pipeline transport temperature.

For all Newtonian hydraulic smooth intervals, unavoidable thermal destroyed exergy has an approximately linear relationship with pipeline length. The wax layer is formed by the precipitation of wax crystals in the Newtonian hydraulic smooth wax precipitation interval, which has a thermal insulation effect; thus, the calculated value of unavoidable thermal destroyed exergy is the lowest. Moreover, the crude oil viscosity increases gradually with the decrease of the pipeline transportation temperature. Both the pressure drop for crude oil safety and economic transportation and the calculated value of unavoidable pressure destroyed exergy increase gradually.

\subsection{Influence of Design Parameters on Unavoidable Destroyed Exergy Loss}

The parameters used to analyze unavoidable destroyed exergy in pipeline transportation may be design parameters or operation parameters. Correspondingly, there are two types of analysis: design exergy analysis and operation exergy analysis. Design exergy analysis evaluates the design quality of the oil pipeline in terms of energy consumption to improve pipeline design and reduce energy consumption. This chapter studies unavoidable destroyed exergy in terms of oil pipe diameter, insulation thickness and buried depth.

\subsubsection{Change with Pipeline Diameter}

Waxy crude oil diameter is varied $(168,219,273$ and $323 \mathrm{~mm})$. Destroyed exergy of pipe transportation is calculated and destroyed exergy distribution curves are shown in Figure 5. 


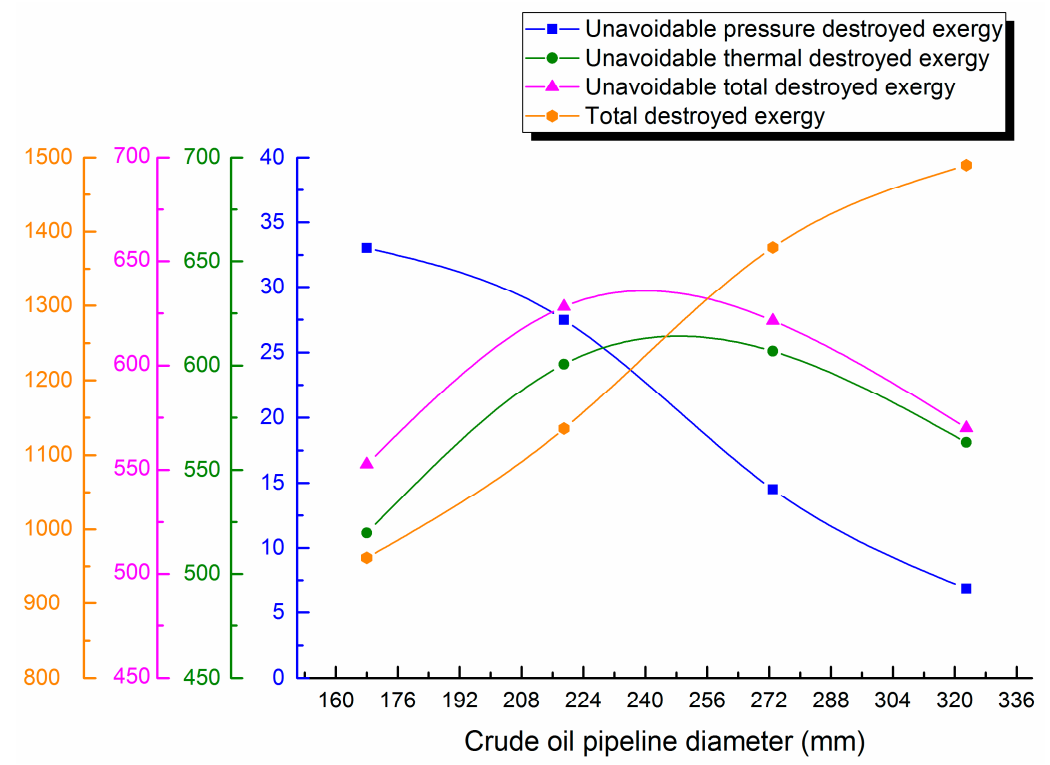

Figure 5. Unavoidable pressure destroyed exergy, unavoidable thermal destroyed exergy, unavoidable total destroyed exergy and total destroyed exergy against diameter.

From the curves, it can be seen that flow velocity in the crude oil pipe decreases with the increase of pipeline diameter, which makes the pressure difference reduce gradually to ensure the safe and economical crude oil transportation. Correspondingly, unavoidable pressure destroyed exergy decreases gradually during pipeline transportation. However, because of its smaller proportion, unavoidable thermal destroyed exergy during pipeline transportation is basically same as unavoidable total destroyed exergy. That is, it first increases significantly, then decreases, but the overall variation does not exceed $15 \%$. Due to the rise of flow, the Newtonian wax precipitation interval lengthens, and the Newtonian no-wax precipitation interval shortens. When the pipe diameter is $323 \mathrm{~mm}$, Non-Newtonian turbulent flow occurs in the pipeline, and the overall heat transfer coefficient of the oil pipeline increases first and then decreases. Accordingly, the temperature difference first increases and then decreases as a driving force for crude oil transportation, which significantly increases the unavoidable thermal destroyed exergy. Additionally, the total destroyed exergy in pipe transportation increases with pipe diameter. Therefore, avoidable destroyed exergy first decreases and then increases with the changed pipe diameter. Thus, save energy and reduce consumption for a waxy crude oil pipeline, the optimal diameter must to be determined. The length and terminal temperature of the crude oil pipeline under different diameters are shown in Table 4:

Table 4. Crude oil pipeline temperature intervals under different pipe diameters.

\begin{tabular}{cccccc}
\hline \multicolumn{2}{c}{ Pipeline Diameters } & $\mathbf{1 6 8} \mathbf{~} \mathbf{m}$ & $\mathbf{2 1 9} \mathbf{~ m m}$ & $\mathbf{2 7 3} \mathbf{~} \mathbf{m m}$ & $\mathbf{3 2 3} \mathbf{~ m m}$ \\
\hline \multirow{2}{*}{$\begin{array}{c}\text { Interval length of pipe } \\
\text { transmission }(\mathrm{km})\end{array}$} & Newton no-wax precipitation & 37.450 & 28.877 & 24.816 & $\mathbf{2 1 . 6 8 5}$ \\
& Newton wax precipitation & 7.671 & 16.244 & 20.305 & 21.631 \\
& non-Newton turbulence & $/$ & $/$ & $/$ & 1.805 \\
\hline \multirow{2}{*}{ End point temperature } & Newton no-wax precipitation & 43.83 & 47.81 & 47.64 & 47.86 \\
$\left({ }^{\circ} \mathrm{C}\right)$ & Newton wax precipitation & 40.47 & 40.26 & 37.39 & 36.61 \\
& non-Newton turbulence & $/$ & $/$ & $/$ & 35.85 \\
\hline \multicolumn{2}{c}{ Theoretical outstation temperature $\left({ }^{\circ} \mathrm{C}\right)$} & 41.32 & 43.44 & 43.64 & 42.57 \\
\hline
\end{tabular}

\subsubsection{Change with Insulation Layer Thickness}

Waxy crude insulation layer thickness is varied (20, 30, 40, 50 and $60 \mathrm{~mm}$ ). Destroyed exergy during pipe transportation is calculated and destroyed exergy distribution curves are shown in Figure 6. 


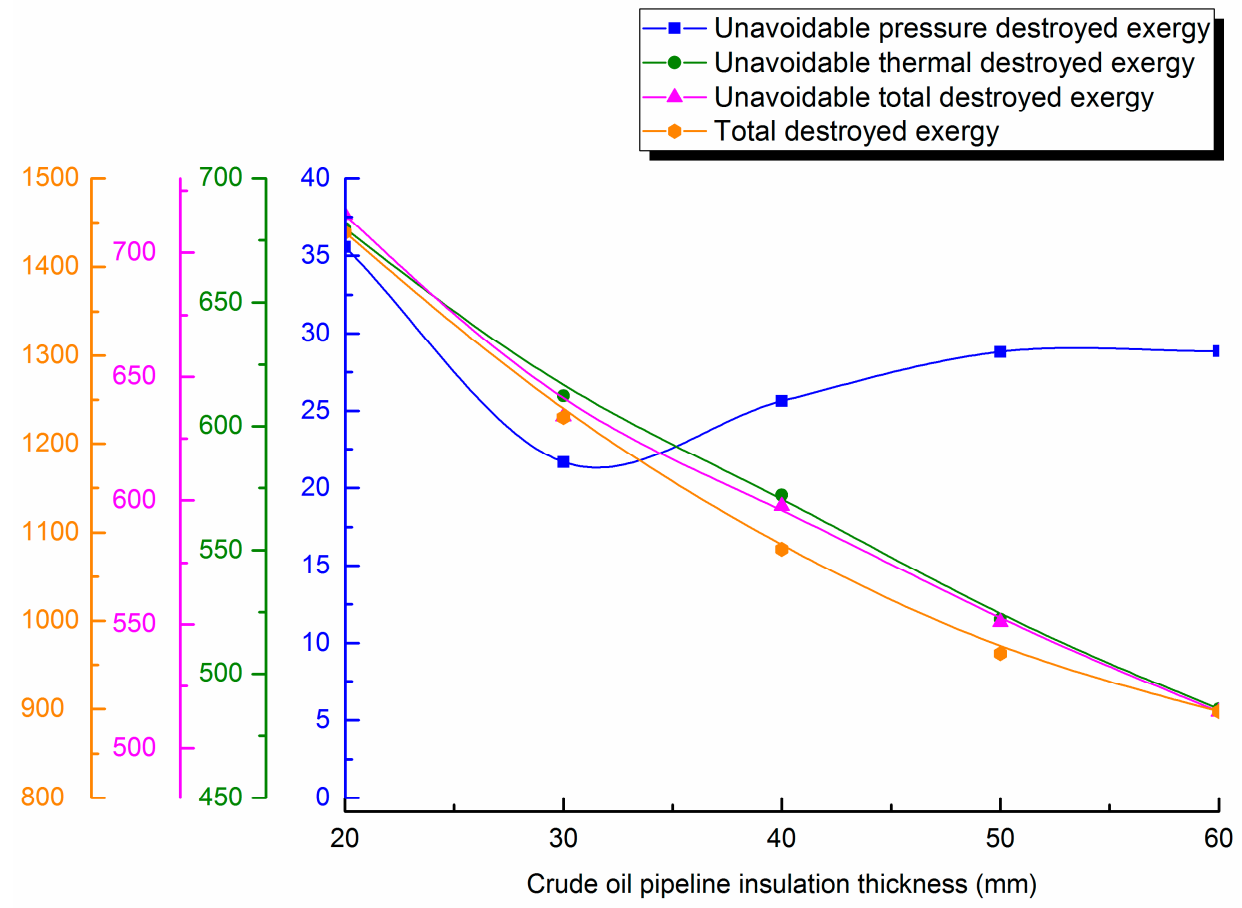

Figure 6. Unavoidable pressure destroyed exergy, unavoidable thermal destroyed exergy, unavoidable total destroyed exergy and total destroyed exergy against insulation thickness.

It can be seen from the curves in the figure that increasing insulation thickness first decrease pressure destroyed exergy and then gradually increases it. However, because of its small proportion, unavoidable thermal destroyed exergy in pipeline transportation is basically consistent with the downward trend of unavoidable total destroyed exergy. This is because, with the gradual increase of insulation layer thickness, the total heat transfer coefficient of the pipe gradually decreases, and the insulation performance improves. The temperature difference decreases correspondingly to ensure smooth transportation, which decreases the unavoidable destroyed exergy. Additionally, total destroyed exergy in the pipeline decreases with increased insulation layer thickness, and the reduction trend slows. Therefore, to save energy and optimize waxy crude oil pipeline operations, it is necessary to consider the relationship between insulation layer thickness and destroyed exergy to determine the optimum thickness of the insulation layer.

\subsubsection{Change with Buried Depth}

The waxy crude buried depth is varied (800, 1200, 1600, 1800 and $2000 \mathrm{~mm})$. Destroyed exergy during pipe transportation are calculated and destroyed exergy distribution curves are shown in Figure 7.

It can be seen in the curves of the figure that unavoidable pressure destroyed exergy decreases slightly with the gradual increase of buried depth, but the proportion decreases, which causes unavoidable thermal destroyed exergy in the pipeline to basically remain consistent with the downward trend of unavoidable total destroyed exergy. This is because, with the gradual increase of buried depth, the total heat transfer coefficient of the pipe gradually decreases, which decreases unavoidable destroyed exergy. Additionally, the total destroyed exergy in the pipeline gradually decreases with increased insulation layer thickness, and the reduction trend slows. Therefore, to save energy and optimize waxy crude oil pipeline operations, it is necessary to consider the relationship between buried depth and destroyed exergy to determine the optimum buried depth for transportation. 


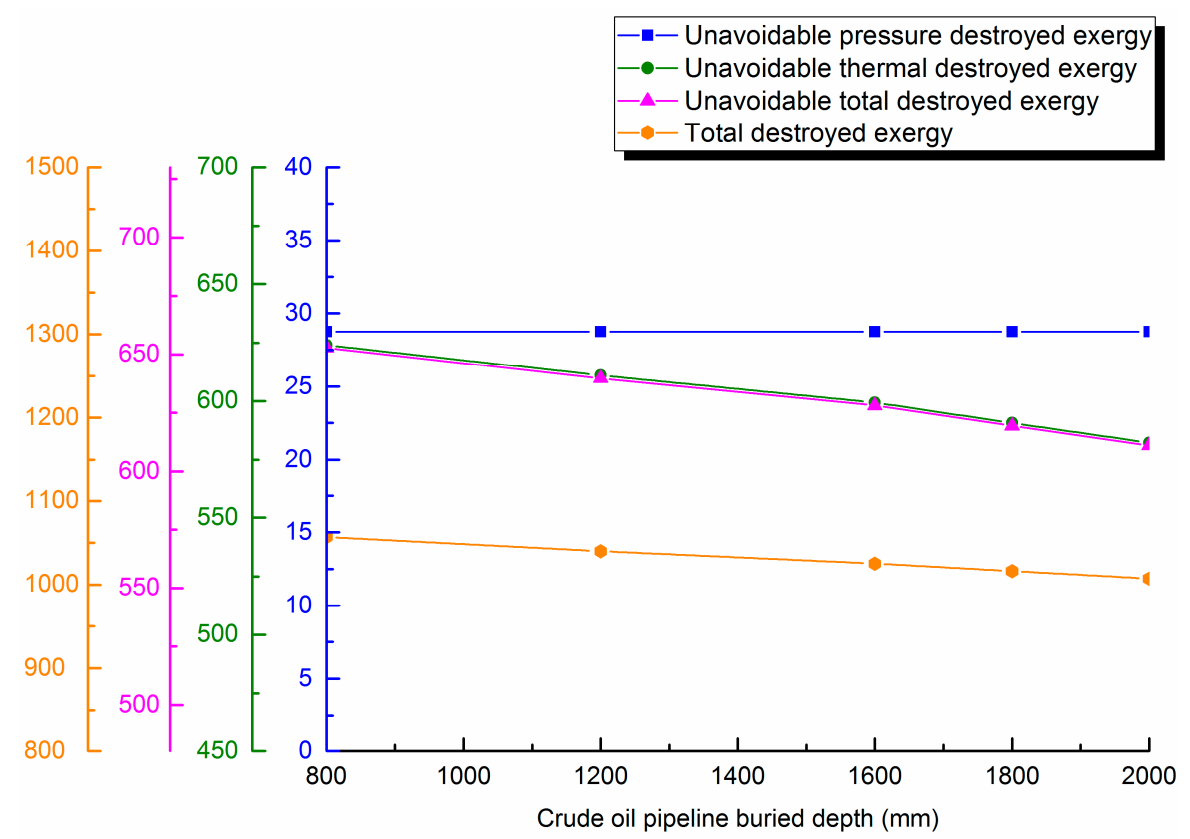

Figure 7. Unavoidable pressure destroyed exergy, unavoidable thermal destroyed exergy, unavoidable total destroyed exergy and total destroyed exergy against buried depth.

\subsection{Influence of Operational Parameters on Unavoidable Destroyed Exergy}

The effects of operational parameters, such as throughput, outstation temperature and outstation pressure, on unavoidable destroyed exergy are as follows:

\subsubsection{Throughput}

Waxy crude throughput is varied $\left(50,60,70,80,90\right.$ and $\left.100 \mathrm{~m}^{3} / \mathrm{h}\right)$. Destroyed exergy during pipe transportation is calculated and destroyed exergy distribution curves are shown in Figure 8.

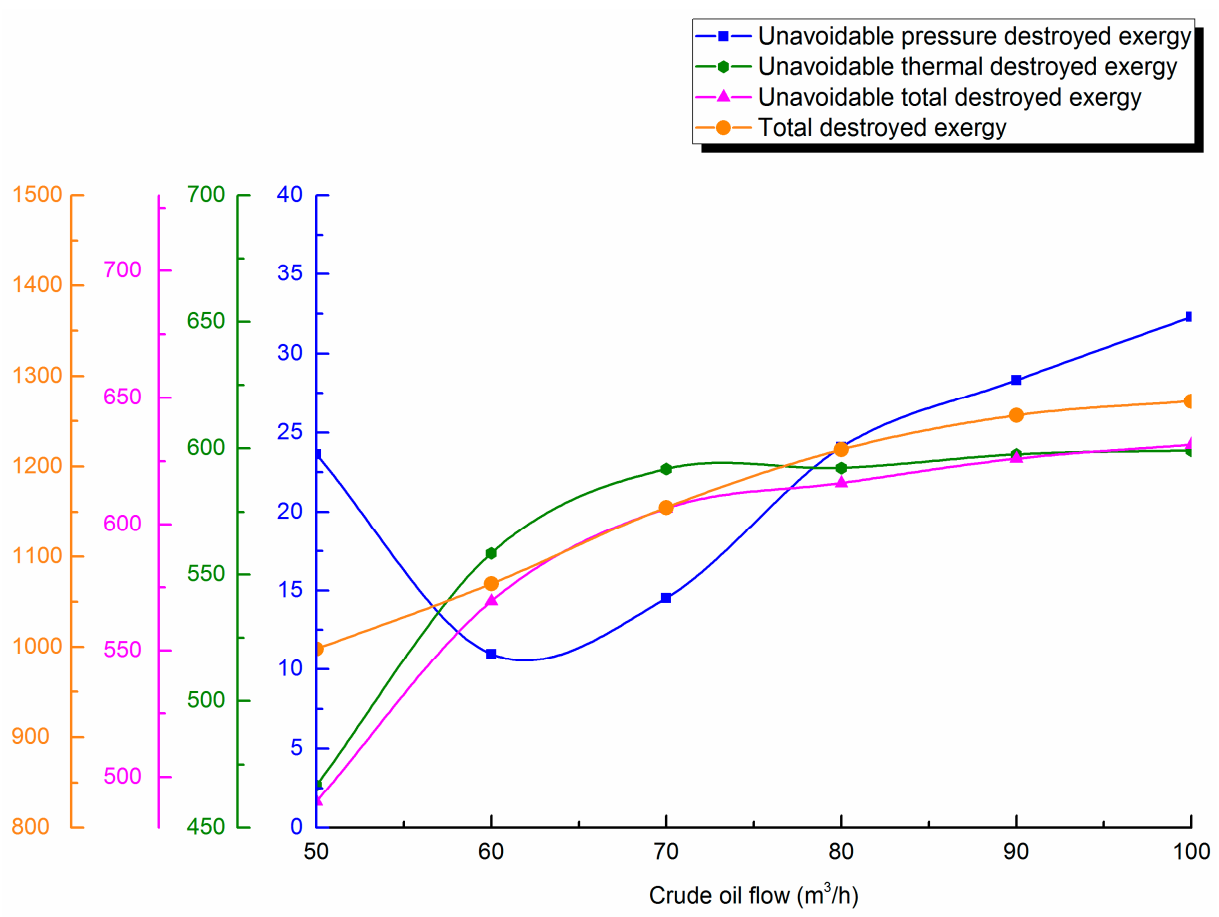

Figure 8. Unavoidable pressure destroyed exergy, unavoidable thermal destroyed exergy, unavoidable total destroyed exergy and total destroyed exergy against throughput. 
From Figure 8, it can be seen that crude oil throughput rises, and unavoidable pressure destroyed exergy first decreases and then gradually increases, although the proportion decreases. This causes unavoidable thermal destroyed exergy in the pipeline to basically remain consistent with the unavoidable total destroyed exergy change trend. It increases significantly first, and then slows. This is related to heat dissipation during pipeline transportation. The heat transfer coefficient of crude oil in the Newtonian interval is the largest, the non-Newtonian turbulence interval is second, and the non-Newtonian laminar flow interval is the smallest. With the increase of throughput, the Newtonian interval lengthens during pipeline transportation, but the non-Newtonian interval shortens. When throughput increased from $50 \mathrm{~m}^{3} / \mathrm{h}$ to $60 \mathrm{~m}^{3} / \mathrm{h}$, the non-Newtonian laminar interval disappears during pipeline transportation, and the Newtonian and non-Newtonian turbulence intervals lengthen. With the increase of the total heat transfer coefficient, a greater temperature difference is needed as a driving force to ensure the smooth transportation of crude oil, which increases unavoidable thermal destroyed exergy in the pipeline. The interval length and heat transfer coefficient of crude oil with different throughputs are shown in Table 5.

Table 5. Calculation results of crude oil pipeline temperature intervals under different throughputs.

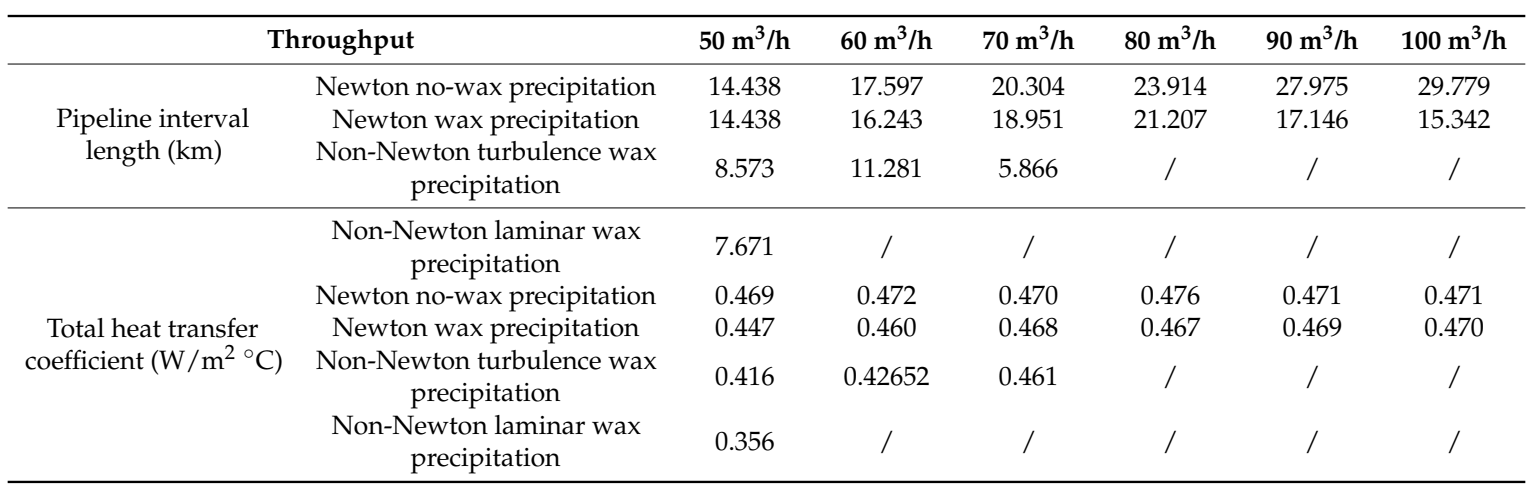

With the gradual increase of the throughput of crude oil, total destroyed exergy in the pipeline will rise correspondingly. The unavoidable total destroyed exergy first increases significantly and then the increasing trend slows. After the increase to $80 \mathrm{~m}^{3} / \mathrm{h}$, the increase unavoidable destroyed exergy will not exceed $2 \%$. This outcome indicates that there is an optimal throughput in waxy crude oil pipeline transportation. When the pipeline exceeds this throughput, the avoidable destroyed exergy of the pipeline can rise, and a large quantity can be lost to the environment. Therefore, the confirmation of optimal crude oil throughput in an oil pipeline is very important to reduce the destroyed exergy of pipeline transportation and ensure the smooth operation of pipeline transportation.

\subsubsection{Outstation Temperature}

Waxy crude outstation temperature is varied $\left(55,60,65,70\right.$ and $\left.75^{\circ} \mathrm{C}\right)$. Destroyed exergy during pipe transportation is calculated and destroyed exergy distribution curves are shown in Figure 9.

It can be seen in the figure that crude oil outstation temperature will first increase and then gradually decrease, and its proportion decreases, which causes unavoidable thermal destroyed exergy in the pipeline to basically remain consistent with the unavoidable total destroyed exergy change trend (which increases significantly first, and then slows). After the increase to $65^{\circ} \mathrm{C}$, the increase of unavoidable destroyed exergy will not exceed $4 \%$. The total destroyed exergy in the pipeline transportation process increases with increased outstation temperature, as does the avoidable destroyed exergy. Therefore, low temperature operation can save energy in crude oil pipeline transportation. However, due to the wax crude oil in China, it is easy to produce condensate pipe accidents at low temperatures. Thus, it is necessary to determine the optimal crude oil outstation temperature to ensure the safe and economic operation of crude oil pipelines. 


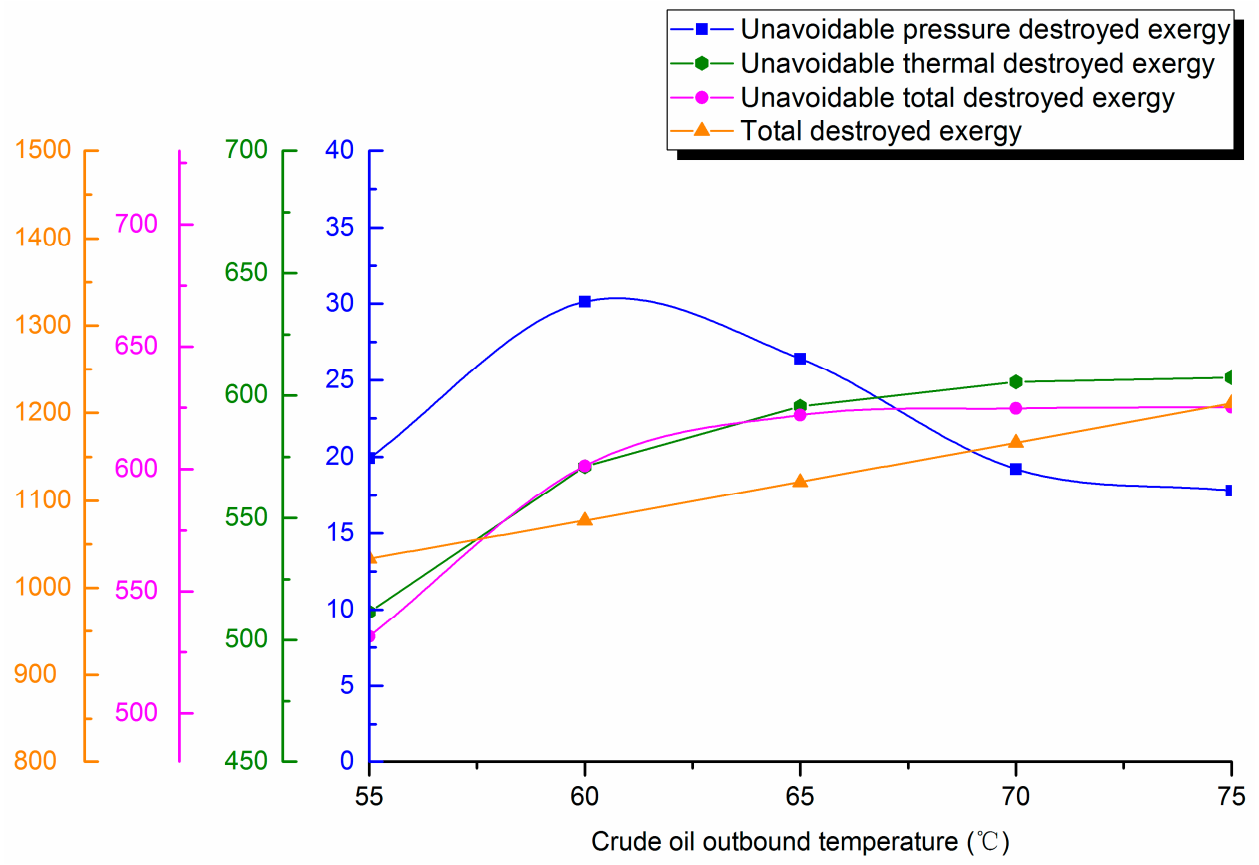

Figure 9. Unavoidable pressure destroyed exergy, unavoidable thermal destroyed exergy, unavoidable total destroyed exergy and total destroyed exergy against outstation temperature.

\subsubsection{Outstation Pressure}

Waxy crude outstation pressure is varied (4000, 4250, 4500 and $5000 \mathrm{kPa})$. Destroyed exergy during pipe transportation is calculated and destroyed exergy distribution curves are shown in Figure 10.

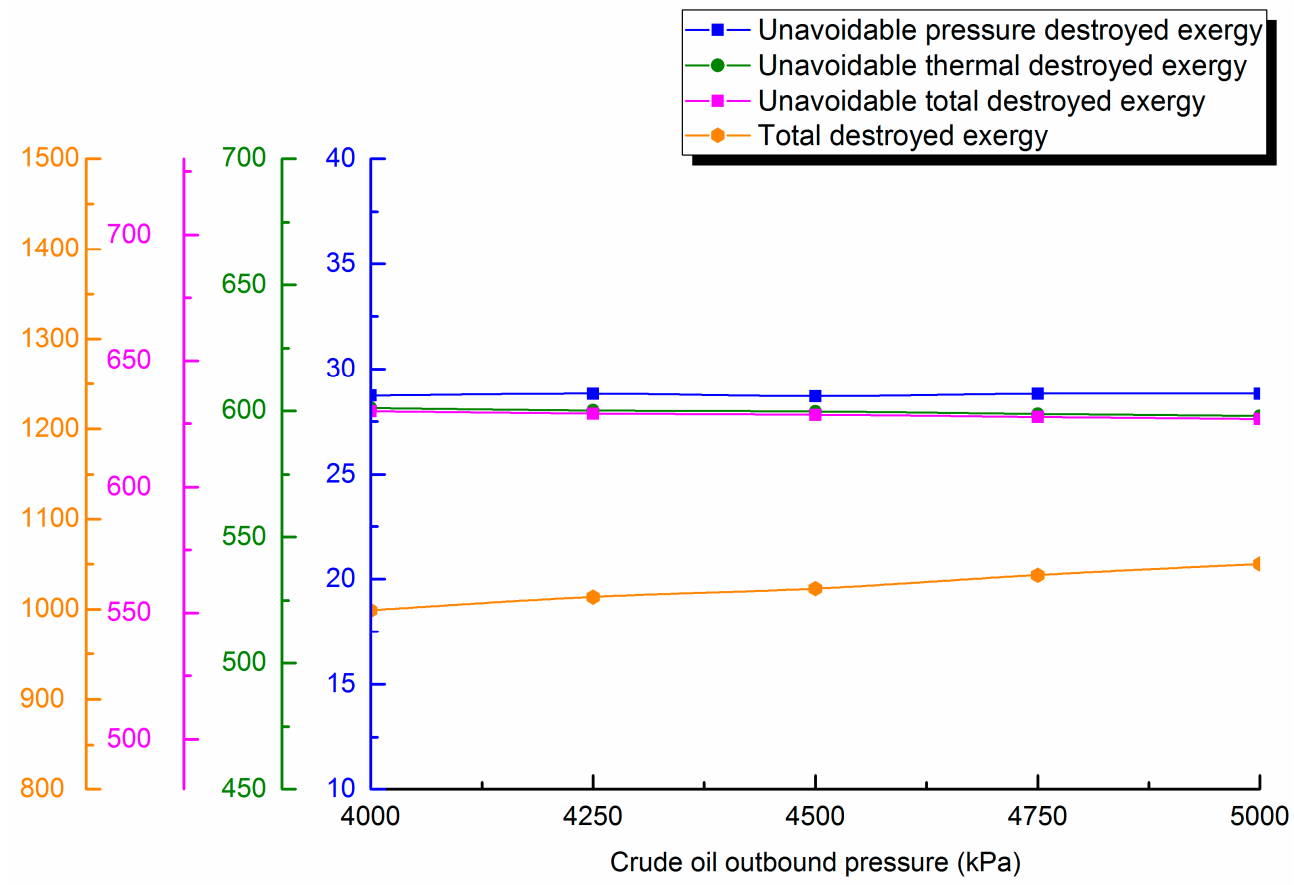

Figure 10. Unavoidable pressure destroyed exergy, unavoidable thermal destroyed exergy, unavoidable total destroyed exergy and total destroyed exergy against outstation pressure.

From the distributions in the figure, unavoidable pressure destroyed exergy decreases slightly with the rise of outstation pressure, but the proportion decreases, which causes unavoidable thermal destroyed exergy in the pipeline transportation process to basically remain consistent with the 
unavoidable total destroyed exergy change trend. There is a slight decrease, but it has a very small effect. Additionally, the total destroyed exergy of the pipeline increases slightly with rising outstation pressure because the change of outstation pressure has little effect on the temperature drop along the pipeline, and so, the change of unavoidable thermal destroyed exergy is very small. In addition, the change of crude oil viscosity is relatively small, which ensures that the unavoidable destroyed exergy changes less for oil safety and economic transmission. Therefore, it is necessary to further consider the relationship between outstation pressure and destroyed exergy to ensure optimal energy conservation operation by determining the optimum outstation pressure of the wax crude oil pipeline.

\section{Conclusions}

(1) Irreversible phenomena, such as heat transfer and flow in a crude oil pipeline, inevitably lead to destroyed exergy. However, conventional exergy analysis is based on the ideal process of non-drive power and can suggest possible process improvements, but cannot determine whether the improvement is feasible. Based on the minimum theoretical temperature and pressure drops required in the crude oil safe transportation, unavoidable and avoidable destroyed exergy are defined. Energy savings will be changed from a general reduction of destroyed exergy to decrease the unavoidable destroyed exergy as far as possible.

(2) Wax crystallization can transform crude oil from a Newtonian fluid to non-Newtonian fluid. Therefore, to consider the influence of wax precipitation on unavoidable destroyed exergy during pipe transmission, it is necessary to divide the pipeline into intervals according to the wax precipitation point, anomalous point and flow transformation temperature. The formulas for unavoidable destroyed exergy of oil products under different flow conditions are derived, which comprehensively consider the flow characteristics of oil products in those transportation intervals. Compared with the simple assumption that the oil in the pipeline is in a single Newtonian flow state, this method can reflect the actual loss of the pipeline.

(3) The applied example shows unavoidable thermal destroyed exergy in waxy crude oil pipeline transportation accounts for the majority of the unavoidable destroyed exergy, reaching $95-99 \%$. The maximum and minimum unavoidable destroyed exergy in different intervals are $381.128 \mathrm{~kJ} / \mathrm{s}$ and $30.259 \mathrm{~kJ} / \mathrm{s}$. The unavoidable destroyed exergy of the whole pipeline $742.934 \mathrm{~kJ} / \mathrm{s}$. It is necessary to further analyze the variation of unavoidable destroyed exergy with different design and operational parameters during pipeline transportation. The research shows that with the rise of the oil pipeline diameter, unavoidable destroyed exergy will first increase up to $625 \mathrm{~kJ} / \mathrm{s}$, then gradually decrease, and the overall variation will not exceed $15 \%$. With the increase of insulation layer thickness, unavoidable destroyed exergy will decrease. The unavoidable pressure destroyed exergy is least at $22 \mathrm{~kJ} / \mathrm{s}$ in $30 \mathrm{~mm}$. Unavoidable destroyed exergy decreases slightly with the lower burial depths. Unavoidable destroyed exergy will settle in $610 \mathrm{~kJ} / \mathrm{s}$, but the increase amplitude will not exceed $2 \%$ after crude oil throughput arrives at $80 \mathrm{~m}^{3} / \mathrm{h}$. With the rise of outstation temperature, unavoidable destroyed exergy first increases significantly, then the increase trend slows, especially when the outstation temperature rises to above $65^{\circ} \mathrm{C}$; the increase of unavoidable destroyed exergy will not be more than $4 \%$ at $618 \mathrm{~kJ} / \mathrm{s}$. With the rise of outstation pressure, unavoidable destroyed exergy will increase slightly. The above research results show that it is necessary to determine the optimal parameters for waxy hot oil pipeline transportation for energy conservation.

Through theoretical and case study, we further deepen the analysis. The unavoidable destroyed exergy calculation can find out the weak links of energy. And it can be adjusted by changing the different working conditions to achieve the most effective results. For example. In the practical engineering application, it is necessary to keep the high flow and the outstation pressure stable, enlarge the diameter as far as possible, increase the thickness of insulation layer and raise the outstation temperature within the scope of meeting the relevant standards. It plays an important role in the research of waxy crude oil pipeline. 
Author Contributions: Conceptualization, Q.C.; Formal Analysis, J.Y.; Investigation, Y.G.; Resources, Y.L.; Data Curation, L.Y.; Writing-Review \& Editing, A.Z.

Funding: This work was financially supported by the National Natural Science Foundation of China (51534004), the Northeast Petroleum University "National Fund" Cultivation Fund (2017PYZL-07).

Conflicts of Interest: The authors declare no conflict of interest.

\section{Nomenclature}

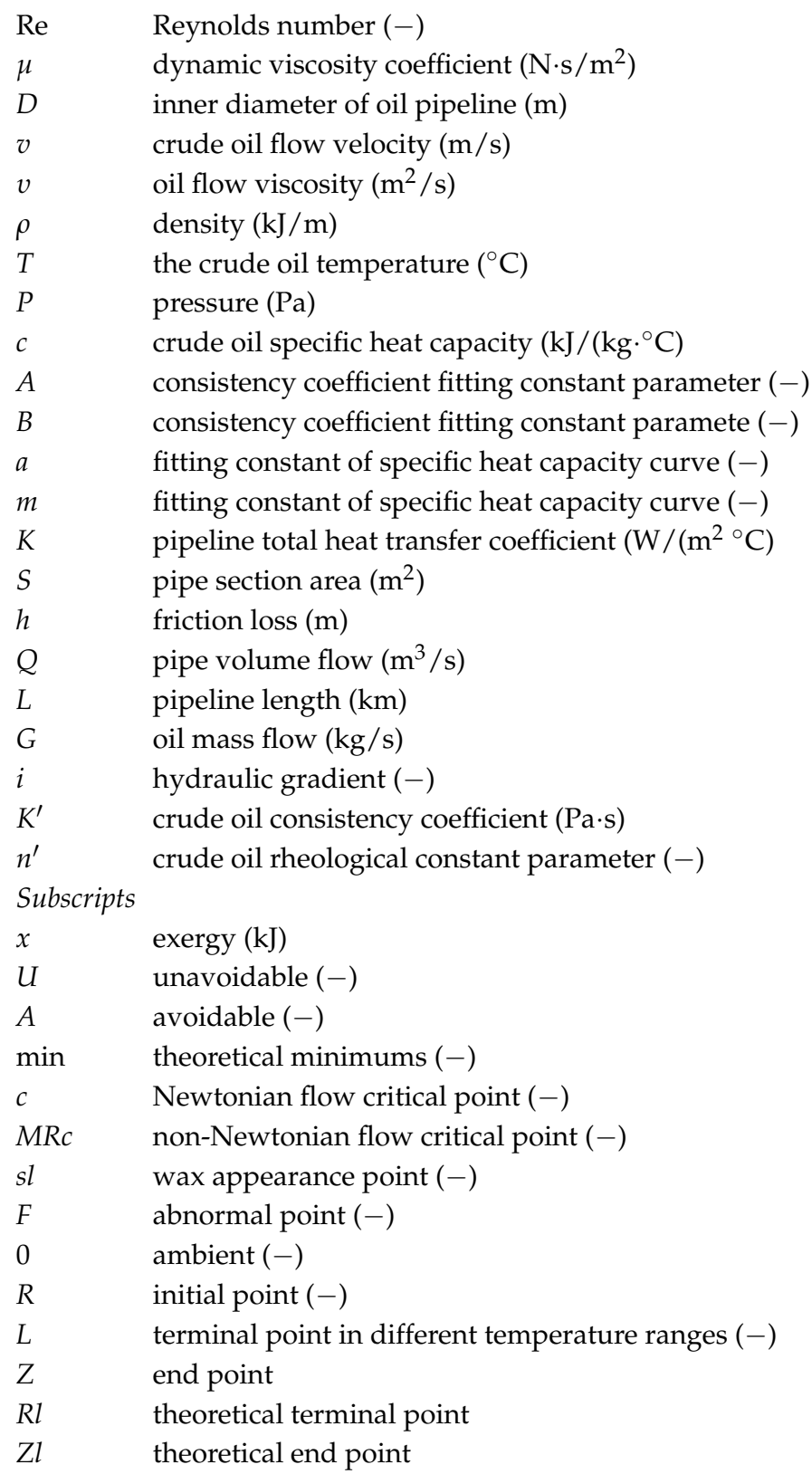

\section{References}

1. Hou, L.; Qi, S.M.; Li, J. Thoughts on energy conservation and consumption reduction of crude oil pipeline transportation system. J. Oil-Gasfield Surf. Eng. 2008, 27, 62-63.

2. Wang, H.C.; Zhang, Y.G.; Fan, A.F. Improvement of gas consumption evaluation method for crude oil gathering and transportation system. J. Oil-Gasfield Surf. Eng. 2001, 20, $24-25$. 
3. Zuo, L.L.; Liu, B.; Wu, C.C.; Xing, X.K.; Chou, J. Application of energy consumption indicators based on hydraulic horsepower in the analysis of energy consumption of oil and gas pipeline. J. Oil Gas Storage Transp. 2012, 301-303. [CrossRef]

4. Probert, S.D.; Chu, C.Y. Internally insulated hot-oil pipelines. J. Appl. Energy 1983, 13, 1-13. [CrossRef]

5. Nguyen, T.V.; Voldsund, M.; Breuhaus, P. Energy efficiency measures for offshore oil and gas platforms. J. Energy 2016. [CrossRef]

6. Belli, M.; Sciubba, E. Extended Exergy Accounting as a general method for assessing the primary resource consumption of social and industrial systems. J. Int. J. Exergy 2007, 4, 421-440. [CrossRef]

7. Sciubba, E. Why Emergy- and Exergy Analysis are non-commensurable methods for the assessment of energy conversion systems. J. Int. J. Exergy 2009, 6, 523-549. [CrossRef]

8. Chen, B.; Dai, J.; Sciubba, E. Ecological accounting for China based on extended exergy. J. Renew. Sustain. Energy Rev. 2014, 37, 334-347. [CrossRef]

9. Lucia, U.; Sciubba, E. From Lotka to the entropy generation approach. J. Phys. A Stat. Mech. Appl. 2013, 392, 3634-3639. [CrossRef]

10. Zhang, M. Description and Analysis of Thermodynamics Exergy Flow in Oil Pipeline Transportation System. Master's Thesis, North East Petroleum University, Daqing, China, 2013.

11. Li, Z. Establishment and Application of Multi-level Exergy Transfer Evaluation System for Energy Consumption in Crude Oil Pipeline. Master's Thesis, North East Petroleum University, Daqing, China, 2014.

12. Fu, Q.S. Thermodynamic Analysis Method of Energy System; Jiaotong University Press: Xi'an, China, 2005; ISBN 7-5605-1944-X.

13. Tsatsaronis, G.; Park, M.H. On avoidable and unavoidable exergy destructions and investment costs in thermal systems. J. Energy Convers. Manag. 2002, 43, 1259-1270. [CrossRef]

14. Zhang, F.T. A Research on the Flow Characteristics of Waxy Crude Oil Pipeline. Master's Thesis, Harbin Institute of Technology, Harbin, China, 2007.

15. Li, X.Y.; Liu, D.J.; Ma, Y.; Wang, F.; Gao, Z. Effect of wax deposit area in waxy hot oil pipeline on whole running conditions. J. Oil Gas Storage Transp. 2014, 33, 46-49. [CrossRef]

16. Ye, D.W.; Han, X.C.; Yan, D.F. Design Specification for Oil Pipeline Process, GB 50253-2003; Planning Press: Beijing, China, 2007.

17. Jiang, H.Y. Design and Management of Oil Pipeline; Petroleum Industry Press: Beijing, China, 2010; ISBN 978-7-5021-7886-4.

18. Li, C.X. Rheology of Crude Oil; China University of Petroleum Press: Beijing, China, 2012; ISBN 978-7-5636-2157-6.

19. Yang, X.H. Design and Management of Oil Pipeline; China University of Petroleum Press: Beijing, China, 2013; ISBN 978-7-5636-2241-2.

20. Cheng, Q.L.; Zheng, A.B.; Pan, C.L.; Sun, W.; Liu, Y. Studies on Energy Consumption of Crude Oil Pipeline Transportation Process Based on the Unavoidable Exergy Loss Rate. J. Case Stud. Therm. Eng. $2018,12$. [CrossRef]

21. Cheng, Q.L.; Gan, Y.F.; Su, W.K.; Liu, Y.; Sun, W.; Xu, Y. Research on Exergy Flow Composition and Exergy Loss Mechanisms for Waxy Crude Oil Pipeline Transport Processes. Energies 2017, 10, 1956. [CrossRef]

22. Cheng, Q.L.; Zheng, A.B.; Song, S.; Wu, H.; Lv, L.L.; Liu, Y. Studies on the Exergy Transfer Law for the Irreversible Process in the Waxy Crude Oil Pipeline Transportation. Entropy 2018, 20, 309. [CrossRef]

23. Li, J.X.; Lou, Y.H. Code for Design of Oil-Gas Gathering and Transportation Systems of Oilfield, GB 50350-2015; Planning Press: Beijing, China, 2015.

(C) 2019 by the authors. Licensee MDPI, Basel, Switzerland. This article is an open access article distributed under the terms and conditions of the Creative Commons Attribution (CC BY) license (http:// creativecommons.org/licenses/by/4.0/). 